\title{
Myosin Heavy Chain Gene Expression in Human Heart Failure
}

\author{
Koichi Nakao, ${ }^{\star}$ Wayne Minobe, ${ }^{\ddagger}$ Robert Roden, ${ }^{\ddagger}$ Michael R. Bristow, ${ }^{\ddagger}$ and Leslie A. Leinwand ${ }^{\star}$ \\ $*$ Department of Molecular Cellular and Developmental Biology, University of Colorado, Boulder, Colorado 80309-0347; and $\doteqdot$ Division of \\ Cardiology, Health Sciences Center, University of Colorado, Denver, Colorado 80262-0139
}

\begin{abstract}
Two isoforms of myosin heavy chain (MyHC), $\alpha$ and $\beta$, exist in the mammalian ventricular myocardium, and their relative expression is correlated with the contractile velocity of cardiac muscle. Several pathologic stimuli can cause a shift in the MyHC composition of the rodent ventricle from $\alpha$ - to $\beta$-MyHC. Given the potential physiological consequences of cardiac MyHC isoform shifts, we determined MyHC gene expression in human heart failure where cardiac contractility is impaired significantly. In this study, we quantitated the relative amounts of $\alpha$ - and $\beta$-MyHC mRNA in the left ventricular free walls (LVs) of 14 heart donor candidates with no history of cardiovascular disease or structural cardiovascular abnormalities. This group consisted of seven patients with nonfailing (NF) hearts and seven patients with hearts that exhibited donor heart dysfunction (DHD). These were compared with 19 patients undergoing cardiac transplantation for chronic end-stage heart failure (F). The relative amounts of $\alpha$-MyHC mRNA to total (i.e., $\alpha+\beta)$ MyHC mRNA in the NF- and DHD-LVs were surprisingly high compared with previous reports $(33.3 \pm 18.9$ and $35.4 \pm 16.5 \%$, respectively), and were significantly higher than those in the F-LVs, regardless of the cause of heart failure $(2.2 \pm 3.5 \%, P<0.0001)$. There was no significant difference in the ratios in NF- and DHD-LVs. Our results demonstrate that a considerable amount of $\alpha$-MyHC mRNA is expressed in the normal heart, and is decreased significantly in chronic end-stage heart failure. If protein and enzymatic activity correlate with mRNA expression, this molecular alteration may be sufficient to explain systolic dysfunction in F-LVs, and therapeutics oriented towards increasing $\alpha$-MyHC gene expression may be feasible. (J. Clin. Invest. 1997. 100:2362-2370.) Key words: coronary artery disease • dilated cardiomyopathy $\bullet$ cardiac transplantation $\bullet$ messenger RNA • polymerase chain reaction
\end{abstract}

\section{Introduction}

Numerous changes in myocardial gene expression occur during the adaptation of the heart to chronic overload, and the na-

\footnotetext{
Address correspondence to Leslie A. Leinwand, Ph.D., Department of Molecular Cellular and Developmental Biology, University of Colorado, Boulder, CO 80309-0347. Phone: 303-492-7606; FAX: 303-4928907; E-mail: leinwand@stripe.colorado.edu

Received for publication 13 June 1997 and accepted in revised form 15 September 1997.
}

J. Clin. Invest.

(C) The American Society for Clinical Investigation, Inc. 0021-9738/97/11/2362/09 \$2.00

Volume 100, Number 9, November 1997, 2362-2370

http://www.jci.org ture of these changes could influence the long-term prognosis of patients with congestive heart failure (1). Of those molecules with potential functional significance for cardiac performance, the myosin heavy chains $(\mathrm{MyHCs})^{1}$ are prominent because they are the molecular motors of muscle. Two types of $\mathrm{MyHC}$ are expressed in the mammalian heart, $\alpha$ - and $\beta$-MyHC. The $\alpha$-MyHC has a higher ATPase activity than $\beta$-MyHC, and the contractile velocity of the heart is correlated with the relative amount of each MyHC. While hearts expressing more $\alpha$-MyHC have a more rapid contractile velocity, hearts with more $\beta$-MyHC allow for greater economy in force generation $(2,3)$. The MyHC composition of the ventricular myocardium of small mammals has been reported to be $>90 \% \alpha-\mathrm{MyHC}$ (4-6), whereas that of humans has been reported to be $>95 \%$ $\beta$-MyHC (7-13). Numerous stimuli have been shown to shift the MyHC composition of the rodent heart. For example, elevation of thyroid hormone and exercise increase $\alpha$-MyHC, whereas thyroid depletion, aging, and pressure overload increase $\beta$-MyHC (14). Because of their potential effect on contractile velocity, shifts in myosin composition could be an important component of heart failure. However, because it was reported initially that the normal human heart was largely devoid of $\alpha$-MyHC (7-13), isoform shifts in developing heart failure were thought to be irrelevant.

Most previous work on the MyHC composition of the human heart was performed with immunohistochemistry because of the difficulty in distinguishing the human $\alpha$ - and $\beta$-MyHCs electrophoretically (9) or by peptide mapping $(7,10)$. Immunohistochemistry allows the spatial expression of each isoform to be determined, but is not quantitative, and two different antibodies cannot be compared directly $(15,16)$. Since human $\alpha$ - and $\beta$-MyHCs are $93 \%$ homologous, it is not surprising that the discrimination of cardiac MyHC isoforms is difficult at the protein level (17-20). The results of immunohistochemical analysis were quite varied with reports ranging from $<5$ up to $88 \%$ of myocytes expressing $\alpha$-MyHC $(8,11,12)$. One report based on RNA analysis indicated no expression of $\alpha$-MyHC mRNA in a single normal human heart, but in that case, only one normal patient was examined, who died of breast cancer without information on cardiovascular status (21).

This study was designed to quantitate MyHC gene expression in nonfailing and failing human left ventricles (LVs). We examined samples from the LV free wall of nonfailing (NF) organ donor hearts, acutely failing donor hearts (donor heart dysfunction, DHD [22]), and end-stage failing (F) human hearts by a newly developed quantitative reverse transcription-PCR (RT-PCR) analysis and ribonuclease protection as-

1. Abbreviations used in this paper: CAD, coronary artery disease; DHD, donor heart dysfunction; EF, ejection fraction; F, failing; IDC, idiopathic dilated cardiomyopathy; LV, left ventricle; MyHC, myosin heavy chain; NF, nonfailing; nt, nucleotide(s); RPA, ribonuclease protection assay; RT-PCR, reverse transcription-PCR; VHD, valvular heart disease. 
say (RPA) for MyHC gene expression. We demonstrated dramatic reduction of $\alpha$-MyHC gene expression in the F-LVs compared with the NF- and DHD-LVs.

\section{Methods}

\section{Patients}

All human hearts were provided by the Colorado and Utah Cardiac Transplant Program. LVs from 14 control organ donor candidates (5 males, 9 females, mean age $34.4 \pm 13.9 \mathrm{yr}$ ) and 19 patients undergoing cardiac transplantation ( $\mathrm{F}$ group; 15 males, 4 females, mean age $50.1 \pm 14.6 \mathrm{yr}$ ) were obtained. The 14 control subjects had no cardiac history and no significant structural abnormalities on cardiac donor screening using echocardiography and, in subjects $>50 \mathrm{yr}$ of age, coronary angiography. All control subjects were maintained under intensive care, but seven of those hearts (NF-1-7; see Table I) were excluded ultimately from heart donation because of age, body size, or blood type incompatibility. In all NF heart cases, the echocardiogram revealed normal LV systolic function. The remaining 7 of the 14 control subjects were identified as having acute DHD (DHD-1-7; see Table I), which is thought to be due to myocardial injury from massively increased sympathetic output accompanying brain injury (22). These hearts were excluded from heart donation because of decreased LV systolic function (ejection fraction $[\mathrm{EF}] \leq 45 \%$ ). In all DHD cases, the echocardiogram revealed diffuse hypokinesis without segmental LV wall motion abnormalities. All of the control subjects were given various doses of dopamine to maintain peripheral vascular tone and renal blood flow, and three of the DHD patients were also given dobutamine. For a summary of their causes of coma and clinical characteristics, see Table I. Thyroid status (determined by T4 levels) were available for three control patients (NF-4, DHD-2 and -5) and were within normal range.

F-LVs were procured from 19 patients undergoing cardiac transplantation for chronic end-stage heart failure (F group) with the following diagnoses: nine had an ischemic cardiomyopathy with history of coronary artery disease (CAD) with at least one myocardial infarction, six had an idiopathic dilated cardiomyopathy (IDC), two had a valvular heart disease (VHD), and the remaining two consisted of one end-stage hypertrophic cardiomyopathy and one previous orthotopic heart transplantation in a subject undergoing retransplantation. For their clinical backgrounds, see Table II. All these end-stage heart failure patients were euthyroid, based on thyrotropin-stimulating hormone (TSH) levels performed routinely on pretransplant patients.

In addition, two right atrial myocardial specimens from donor candidates were examined to confirm the accuracy of the methods, as mentioned below.

The investigators were blinded to the clinical evaluation identity of the subjects during gene expression analysis. In all cases, written informed consent was given by a family member or by the transplant patient for research use of the explanted heart.

\section{Tissue preparation}

Hearts were placed in ice-cold oxygenated physiological salt solution immediately after removal, and myocardial specimens were gathered within 10 min of explantation. A transmural specimen was taken from the medial part of the LV free wall when possible, and midway between the apex and base, at least $2 \mathrm{~cm}$ away from the scar, in patients with myocardial infarction. Immediately after sampling, myocardial specimens were frozen in liquid nitrogen, and stored at $-80^{\circ} \mathrm{C}$ until use.

\section{Total RNA extraction}

Total cellular RNA was isolated from frozen LV specimen $(156 \pm 71$ $\mathrm{mg}$, range 35-276 $\mathrm{mg}$ ) using a modification of the acid guanidinium thiocyanate-phenol-chloroform method (23). Briefly, the frozen tissue was homogenized at $4^{\circ} \mathrm{C}$ in $2.0 \mathrm{ml}$ of RNA STAT-60"B" (TelTest, Inc., Friendswood, TX) twice at $13,500 \mathrm{rpm}$ for $30 \mathrm{~s}$ with an Ultra-Turrax homogenizer (IKA-Works, Inc., Cincinnati, OH). After centrifugation $(12,000 \mathrm{~g}$ for $15 \mathrm{~min})$, the aqueous phase was collected, and RNA was precipitated by the addition of the same volume of isopropanol. The RNA pellet was washed with $70 \%$ ethanol and resuspended in diethyl pyrocarbonate-treated water. The concentration of extracted total RNA was determined spectrophotometrically (U-2000; Hitachi Sci. Instrs., Mountain View, CA).

\section{Quantitative RT-PCR}

Reverse transcription. First-strand cDNA was synthesized using reverse transcriptase (SuperScript II RT; GIBCO BRL, Gaithersburg, $\mathrm{MD})$ and random hexamer (GIBCO BRL) from $2 \mu \mathrm{g}$ of extracted total RNA according to the manufacturer's instructions.

$P C R$. Two oligonucleotides (5' primer, 5'-AGCAGAAGCGCAACGCAGAGT-3'; and 3' primer, 5'-TGCTGCACCTTGCGGAACTTG-3') were designed from reported $\alpha$ - and $\beta$-MyHC cDNA sequences $(17,19)$, and synthesized by GIBCO BRL. These primers are identical in sequence in $\alpha$ - and $\beta$-MyHC, and the amplified 217-bp sequence was $96 \%$ identical in $\alpha$ - and $\beta$-MyHC (Fig. 1 ). The $5^{\prime}$ primers are located in exons 36 and 37 of $\alpha$ - and $\beta$-MyHC genes, respectively, while the $3^{\prime}$ primers are in exons 38 and 39, respectively. The amplified regions correspond to nucleotides 5492-5708 and 5572-5788 in $\alpha$ (17) and $\beta$-MyHC cDNA (19), respectively. The two exon/intron boundaries are conserved (17-20).

PCR was carried out in a total volume of $50 \mu$ l containing $10 \mathrm{mM}$ Tris- $\mathrm{HCl}, 50 \mathrm{mM} \mathrm{KCl}, 1.5 \mathrm{mM} \mathrm{MgCl} 2,0.2 \mathrm{mM}$ dNTP, $15 \mathrm{pmol}$ of each primer, and $2.5 \mathrm{U}$ of Taq DNA polymerase (Perkin-Elmer Corp., Norwalk, CT). The mixture was amplified with a thermal cycling system (OmniGene; Hybaid Ltd., Middlesex, UK) under the following conditions. After a hot start at $94^{\circ} \mathrm{C}$ for $3 \mathrm{~min}$, amplification was done over 21 cycles of the following program: $94^{\circ} \mathrm{C}$ for $45 \mathrm{~s}$ for denaturation, $55^{\circ} \mathrm{C}$ for $45 \mathrm{~s}$ for annealing, and $72^{\circ} \mathrm{C}$ for $90 \mathrm{~s}$ for primer extension. It was then kept at $72^{\circ} \mathrm{C}$ for $10 \mathrm{~min}$ and held at $30^{\circ} \mathrm{C}$.

Restriction digestion. The amplified 217-bp fragment was digested with endonucleases PstI or SacI (New England Biolabs, Inc., Beverly, MA). Only $\beta$-MyHC has PstI sites, whereas both MyHCs have SacI sites (Fig. 1). Therefore, the remaining 217-bp bands after digestion with PstI and SacI correspond to amplified $\alpha$-MyHC cDNA and background, respectively. Digestion was performed in a total volume of $20 \mu \mathrm{l}$ containing $5 \mu \mathrm{l}$ of PCR product, with appropriate buffers, with (PstI, $20 \mathrm{U}$, or SacI, $20 \mathrm{U}$ ) or without (replaced by distilled water) restriction enzyme, at $37^{\circ} \mathrm{C}$ for $3 \mathrm{~h}$ according to the manufacturer's instructions.

Quantification of amplified $\alpha-M y H C c D N A$ ratio. The digested fragments were subjected to $8 \%$ polyacrylamide gel electrophoresis $(8 \mu \mathrm{l}$ of $20 \mu \mathrm{l}$ reaction, room temperature, $10 \mathrm{~V} / \mathrm{cm}$ constant) with a Mighty Small II apparatus (Hoefer Pharmacia Biotech Inc., San Francisco, CA). The gel was stained with CYBR green I (diluted 1:10,000; Molecular Probes, Inc., Eugene, OR) for 60 min with gentle agitation. The digested fragments were separated clearly from the original 217 bp band. The fluorescence signal of amplified and digested bands was detected using a fluorescence imaging system (STORM; Molecular Dynamics, Sunnyvale, CA), and the intensity was evaluated with a quantification program (ImageQuant; Molecular Dynamics). The relative amount of amplified $\alpha$-MyHC cDNA to total $(\alpha+\beta)$ MyHC cDNA was determined using the following formula:

Amplified $\alpha$-MyHC cDNA ratio $(\%)=$ $100\left(S I_{\mathrm{PstI}}-S I_{\text {SacI }}\right) /\left(S I_{\mathrm{Enz}-}-S I_{\text {SacI }}\right)$,

where $S I_{\mathrm{Pst}}, S I_{\mathrm{Sac}}$, and $S I_{\mathrm{Enz}-}$ are the signal intensity (arbitrary units) of 217-bp bands after incubation with PstI, with SacI, and without endonuclease, respectively.

\section{Quantification with RPA}

To verify the accuracy of the newly developed quantitative RT-PCR, RPA was also performed using the same specimens.

Antisense riboprobe. To prepare the template of antisense ribo- 


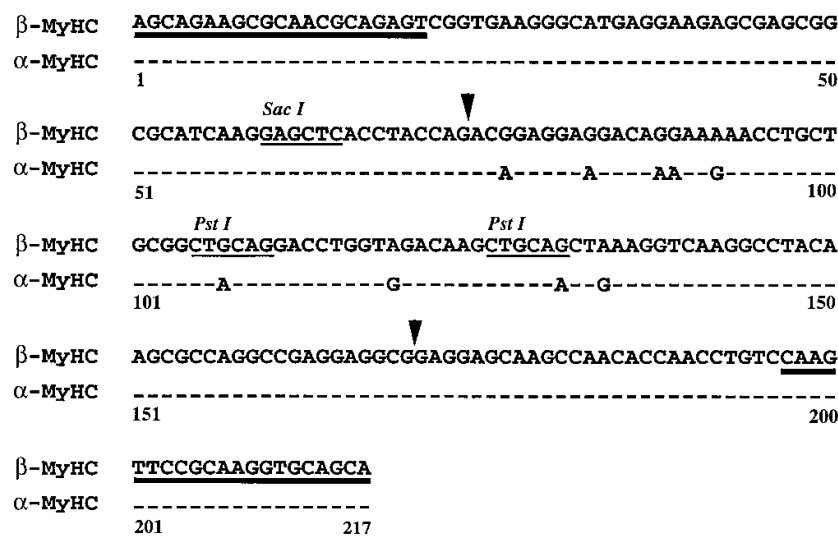

Figure 1. Comparison of the amplified 217-bp cDNA sequences of $\alpha$ - and $\beta$-MyHCs. The amplified regions correspond to nt numbers 5492-5708 in $\alpha$ - (reference 17) and 5572-5788 in $\beta$-MyHC cDNA (reference 19), respectively. The amplified nt sequences are $96 \%$ identical. Bold underlining, Primer annealing sites. SacI and PstI restriction sites are indicated. Arrowheads, Two exon/intron junctions.

probe, $\beta$-MyHC cDNA (282 bp, nucleotides [nt] 3588-3869 [19]) was amplified from the extracted human LV RNA (patient F-10) using two oligonucleotides (5'-primer, 5'-GAGGCCGAGTTCCAGAAGATG-3'; and 3'-primer, 5'-GCTCCGGTGCTCATTCATCTG-3') as mentioned above. The cDNA was cloned with PCRscript II (Stratagene Inc., La Jolla, CA) and sequenced (Fig. 2). The nt sequence was $94 \%$ identical in $\alpha$ - and $\beta$-MyHC cDNA within this region. In particular, the $5^{\prime}$ region (1-227) was completely identical. The antisense riboprobe (332-nt) was generated with T3 RNA polymerase (Stratagene Inc.), and labeled by $\left[\alpha{ }^{32} \mathrm{P}\right] \mathrm{UTP}$ (Amersham Corp., Arlington Heights, IL) using Transcription in vitro Systems (Promega Corp., Madison, WI), and purified by guanidinium-acid phenol extraction followed by isopropanol precipitation.

$R P A$. RPA was performed using the RPA II kit (Ambion Inc., Austin, TX). Briefly, 500,000 cpm $\left(\left[\alpha-{ }^{32} \mathrm{P}\right] \mathrm{UTP}\right)$ of probe was combined with $2.5 \mu \mathrm{g}$ RNA and hybridized for $20 \mathrm{~h}$ at $45^{\circ} \mathrm{C}$ in hybridization buffer. Samples were digested at $37^{\circ} \mathrm{C}$ for $30 \mathrm{~min}$ with $20 \mathrm{U} \mathrm{T} 1$ RNase and $1 \mu \mathrm{g}$ RNase A in $200 \mu \mathrm{l}$ digestion buffer according to the manufacturer's instructions. After RNase inactivation and precipitation, the samples were subjected to electrophoresis on a $6 \%$ acrylamide gel under denaturing conditions. The sizes of protected fragments were determined by coelectrophoresis with the SequaMark DNA size ladder (Research Genetics, Inc., Huntsville, AL). The 282nt riboprobe was protected when it was hybridized with $\beta$-MyHC mRNA, while two protected fragments of 239 and $227 \mathrm{nt}$ were observed when the riboprobe was hybridized with $\alpha$-MyHC mRNA, because of the difficulty of digestion at the site of one nt mismatch (nt 228, Fig. 2).
Quantification of protected fragments. The radioactivity of protected fragments was detected with a PhosphorImager (STORM; Molecular Dynamics) and quantified using ImageQuant (Molecular Dynamics). The relative amount of $\alpha$-MyHC mRNA to total $(\alpha+\beta)$ MyHC mRNA was expressed in the following formula, taking into consideration the difference in the amount of $\left[\alpha-{ }^{32}\right.$ P]UTP incorporated into each protected riboprobe:

$\alpha$-MyHC mRNA expression ratio $(\%)=$ $100\left(1.2 V_{\alpha 1}+1.3 V_{\alpha 2}\right) /\left(V_{\beta}+1.2 V_{\alpha 1}+1.3 V_{\alpha 2}\right)$,

where $V_{\beta}, V_{\alpha 1}$, and $V_{\alpha 2}$ are the radioactivities of protected fragments, 282, 239, and $227 \mathrm{nt}$ long, respectively.

\section{Statistical analysis}

Data were expressed as mean \pm SD. The values were analyzed by the nonparametric analogues of ANOVA and the two-tailed $t$ test, which are the Kruskal-Wallis and the Wilcoxon rank-sum test, respectively. By Kruskal-Wallis, $P=0.0001$. By Wilcoxon, for comparisons of NF vs. DHD, NF vs. F, and DHD vs. F hearts, $P$ values were 1.000, 0.0001 , and 0.0001 , respectively.

\section{Results}

Quantitative assessment of amplified PCR products. Based on the known correlation between increased contractility and $\alpha$-MyHC content of the rodent heart, we wished to determine the amount of $\alpha$-MyHC in the normal human heart and whether there is a decrease in $\alpha$-MyHC in heart failure. The strategy used was to amplify both $\alpha$ - and $\beta$-MyHC cDNA with a pair of primers whose sequence is identical in the two mRNAs (Fig. 1). The PCR product was then cleaved with an enzyme (PstI) that cleaves the $\beta$ - but not the $\alpha$-MyHC product, and the proportion of $\alpha$-MyHC relative to the total was stained by CYBR green and quantitated. Several controls were carried out to ensure that ( $a$ ) the quantification of the bands was in the linear range of the assay (not shown), (b) the measurements were made in the exponential phase of amplification (Fig. 3), and $(c)$ the $\alpha$ - and $\beta$-MyHC were amplified with equal efficiency (Fig. 3). To ensure the identity of the product, direct sequencing of the 217-bp cDNA was performed for two specimens, DHD-1 and F-1 (Tables I and II). The obtained sequences demonstrated that the fragment from F- 1 was $\beta$-MyHC, whereas the amplified DHD-1 fragment after digestion with Pst corresponded to $\alpha$-MyHC cDNA (data not shown) $(17,19)$. The amplified region spanned two splice junctions (Fig. 1), eliminating the possibility of contaminating genomic DNA. In addition, no amplified product could be seen in a control cDNA reaction prepared in parallel in which reverse transcriptase was omitted (data not shown).

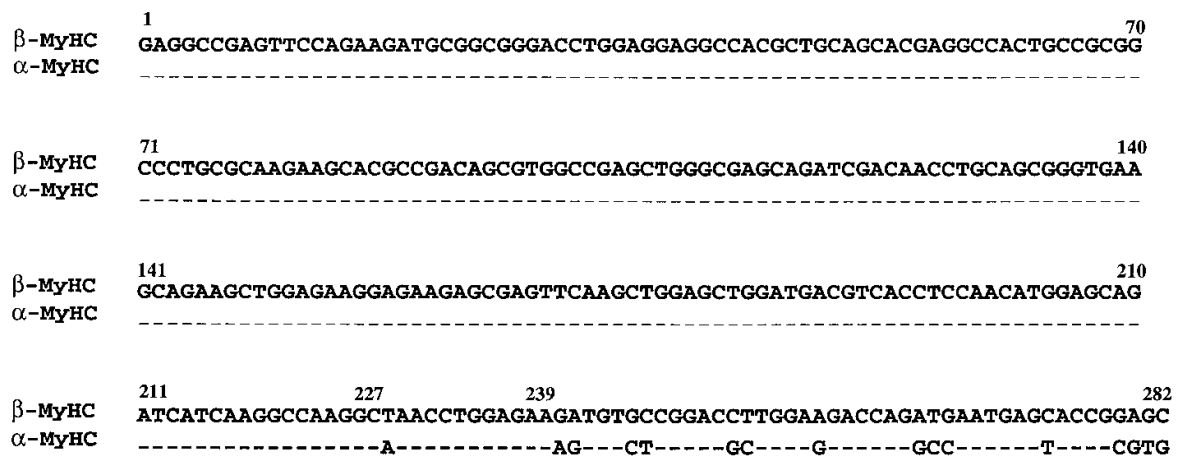

Figure 2. Comparison of the regions of $\beta$ (3588-3869 [reference 19]) and $\alpha$-MyHC (3508-3789 [reference 17]) covered by the ribonuclease protection probe. The $\beta$-MyHC cDNA was used for making the antisense riboprobe. 
A

\begin{tabular}{|c|c|c|}
\hline $\begin{array}{l}\text { PCR } \\
\text { cycle \# }\end{array}$ & 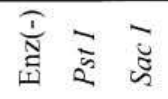 & $\begin{array}{c}\text { Amplified } \alpha-\mathrm{MyHC} \\
\text { cDNA ratio (\%) }\end{array}$ \\
\hline 18 & $\because \quad$ & 18.8 \\
\hline 19 & - & 19.7 \\
\hline 20 & - & 17.7 \\
\hline 21 & $\omega$ & 19.5 \\
\hline 22 & $\omega \omega$ & 20.1 \\
\hline
\end{tabular}

B

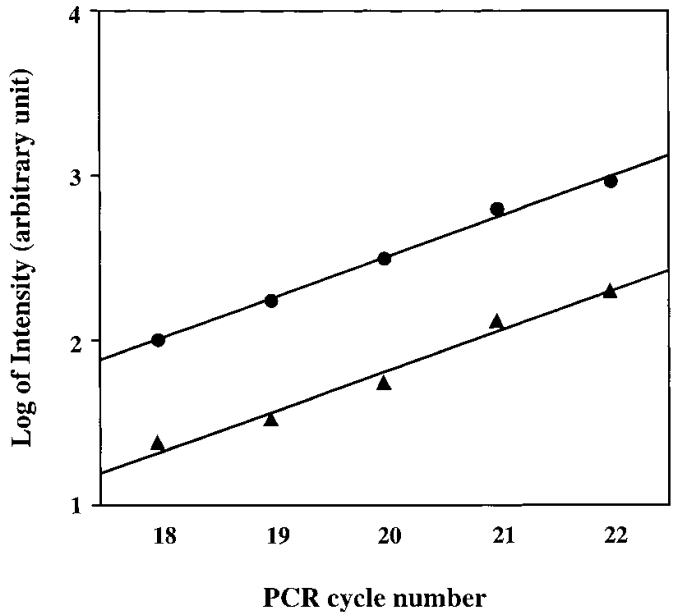

Figure 3. (A) Pattern of MyHC cDNA after restriction digestion over various amplification cycles (cycles 18-22).

Right, Calculated amplified $\alpha-M y H C$ cDNA ratios. (B) Plots of amplification cycle number vs. logarithm of the amount of total MyHC cDNA

(๑) and $\alpha-\mathrm{MyHC}$ cDNA

$(\boldsymbol{\Delta})$. Both show linear correlation, indicating that the amplifications are in the exponential phase of the cycle. Their slopes are equal, suggesting that $\alpha$ - and $\beta$-MyHC cDNA were amplified with equal efficiency.
Amplified $\alpha$-MyHC cDNA ratio in $L V$. The MyHC mRNA composition of the NF-, DHD-, and F-LV samples is shown in Fig. 4. Visual inspection demonstrates that there is a significant amount of $\alpha$-MyHC mRNA in the NF- and DHD-LVs, and there is substantially less in the F-LV ( $P$ lanes). The mean values of total MyHC cDNA [Enz(-) lanes] were not statistically different among all three patient groups: NF-, DHD-, and F-LV $(827 \pm 215,1,062 \pm 570$, and 951 \pm 449 [arbitrary units], respectively). The relative amount of amplified $\alpha-\mathrm{MyHC}$ cDNA to total (i.e., $\alpha+\beta$ ) amplified MHC cDNA is shown in Tables
I and II and Fig. 5. The values obtained for the NF- and DHDLVs were surprisingly high $(33.3 \pm 18.9$ and $35.4 \pm 16.5 \%$, respectively), and significantly higher than those in the F-LV $(2.2 \pm 3.5 \%, P<0.0001)$. There was no significant difference in the ratio between NF- and DHD-LVs.

In the control subjects (i.e., NF + DHD), the amplified $\alpha-\mathrm{MyHC}$ cDNA ratios varied considerably (7.5-61.9\%). The values showed no significant relationship with the duration of life support $\left(r^{2}=0.03\right)$, the dose of dopamine at the organ harvest $\left(r^{2}=0.17\right)$, both variables combined $\left(r^{2}=0.17\right)$, or the age

Table I. Clinical Characteristics and Amplified $\alpha-M y H C$ cDNA Ratios of 14 Organ Donor Controls

\begin{tabular}{|c|c|c|c|c|c|c|c|c|}
\hline Patient No. & Age & Gender & $\begin{array}{c}\text { Cause of } \\
\text { coma }\end{array}$ & $\begin{array}{l}\text { Cardiovascular } \\
\text { abnormality }\end{array}$ & $\mathrm{EF}$ & $\begin{array}{l}\text { Duration of } \\
\text { life support }\end{array}$ & DOP/DOB & $\begin{array}{l}\text { Amplified } \alpha \text {-MyHC } \\
\text { cDNA ratio }\end{array}$ \\
\hline & & & & & $\%$ & $h$ & $\mu g / \mathrm{kg} / \mathrm{min}$ & $\%$ \\
\hline \multicolumn{9}{|l|}{ NF donor } \\
\hline NF-1 & 27 & $\mathrm{~F}$ & MVA & None & NA* & 71 & $8 / 0$ & 54.7 \\
\hline NF-2 & 52 & F & CVA & None & 65 & 48 & $7 / 0$ & 33.1 \\
\hline NF-3 & 50 & F & CVA & None & NA* & 40 & $15 / 0$ & 61.9 \\
\hline NF-4 & 17 & M & $\mathrm{CHI}$ & None & 65 & 61 & $5 / 0$ & 25.7 \\
\hline NF-5 & 55 & $\mathrm{~F}$ & CVA & $\mathrm{CAD}^{\ddagger}$ & 55 & 22 & $7 / 0$ & 7.5 \\
\hline NF-6 & 49 & F & CVA & None & 65 & 18 & $4 / 0$ & 24.0 \\
\hline NF-7 & 38 & M & SIGSW & None & NA* & 20 & $13 / 0$ & 26.0 \\
\hline Mean \pm SD & $41 \pm 14$ & - & - & - & $63 \pm 5$ & $40 \pm 21$ & $8.4 \pm 4.1^{\S}$ & $33.3 \pm 18.9$ \\
\hline \multicolumn{9}{|l|}{ DHD } \\
\hline DHD-1 & 24 & $\mathrm{~F}$ & MVA & None & 25 & 47 & $15 / 4$ & 19.5 \\
\hline DHD-2 & 42 & F & CVA & None & 20 & 66 & $12 / 0$ & 24.1 \\
\hline DHD-3 & 22 & M & SIGSW & None & 30 & 20 & $40 / 0$ & 48.3 \\
\hline DHD-4 & 39 & F & SIGSW & None & 40 & 29 & $15 / 5$ & 15.1 \\
\hline DHD-5 & 33 & $\mathrm{~F}$ & CVA & None & 45 & 37 & $5 / 0$ & 52.6 \\
\hline DHD-6 & 18 & M & CVA & None & 14 & 33 & $15 / 10$ & 33.4 \\
\hline DHD-7 & 16 & M & MVA & None & 30 & 32 & $70 / 0$ & 55.0 \\
\hline Mean \pm SD & $28 \pm 10$ & - & - & - & $29 \pm 11^{\|}$ & $38 \pm 15$ & $25 \pm 23^{\S}$ & $35.4 \pm 16.5$ \\
\hline
\end{tabular}

$D O P / D O B$, dopamine/dobutamine at organ harvest. $M V A$, Motor vehicle accident. $C V A$, Cerebral vascular accident. $C H I$, Closed head injury. SIGSW, Self-inflicted gunshot wound. *Echocardiogram grossly normal but technically inadequate for determination of EF. Incidental CAD ( $30 \%$ narrowing of left anterior descending artery on angiography). ${ }^{\S}$ Mean \pm SD of DOP. ${ }^{\|}<0.00001$ vs. NF group. 


\begin{tabular}{|c|c|c|c|c|c|c|c|c|c|c|}
\hline \multirow[b]{2}{*}{ Patient No. } & \multirow[b]{2}{*}{ Age } & \multirow[b]{2}{*}{ Gender } & \multirow[b]{2}{*}{ Diagnosis } & \multirow{2}{*}{$\begin{array}{l}\text { Surgical/transluminal } \\
\text { interventions }\end{array}$} & \multicolumn{4}{|c|}{ Medical treatments } & \multirow[b]{2}{*}{$\mathrm{EF}$} & \multirow{2}{*}{$\begin{array}{l}\text { Amplified } \alpha-\mathrm{MyHC} \\
\text { cDNA ratio }\end{array}$} \\
\hline & & & & & Dxn & ACEI & Dutx & Ca-blkr & & \\
\hline & & & & & & & & & $\%$ & $\%$ \\
\hline F-1 & 64 & $\mathrm{M}$ & CAD & CABG $\times 5$, PTCA $\times 1$ & + & - & + & - & 25 & 1.8 \\
\hline $\mathrm{F}-2$ & 54 & M & CAD & PTCA $\times 3$ & + & + & + & - & 15 & 2.4 \\
\hline F-3 & 57 & M & CAD & None & + & + & + & - & 15 & 0.0 \\
\hline F-4 & 60 & M & CAD & $\mathrm{CABG} \times 6$ & + & - & + & - & 20 & 1.2 \\
\hline F-5 & 58 & M & CAD & AICD & - & - & - & - & 16 & 0.0 \\
\hline F-6 & 65 & M & CAD & PTCA $\times 1$ & + & + & + & - & 15 & 1.8 \\
\hline F-7 & 59 & M & CAD & $\mathrm{CABG} \times 3$ & + & - & + & + & 30 & 4.6 \\
\hline F-8 & 61 & M & CAD & $\mathrm{CABG} \times 1$ & + & - & + & + & 22 & 14.5 \\
\hline F-9 & 55 & M & CAD & None & + & + & - & - & 21 & 2.6 \\
\hline F-10 & 64 & $\mathrm{~F}$ & IDC & None & NA & NA & NA & NA & 8 & 0.0 \\
\hline F-11 & 34 & M & IDC & None & + & - & - & - & 20 & 0.0 \\
\hline $\mathrm{F}-12$ & 53 & M & IDC & None & + & - & - & - & 10 & 0.6 \\
\hline F-13 & 18 & $\mathrm{~F}$ & IDC & None & + & + & + & + & NA & 6.1 \\
\hline F-14 & 24 & M & IDC & None & + & + & + & - & 20 & 0.0 \\
\hline F-15 & 60 & $\mathrm{M}$ & IDC & AICD & + & + & + & - & 20 & 0.0 \\
\hline F-16 & 29 & $\mathrm{~F}$ & VHD & MVR & + & + & + & - & 10 & 0.4 \\
\hline F-17 & 38 & M & VHD & AVR & + & + & + & - & NA & 3.1 \\
\hline F-18 & 41 & $\mathrm{~F}$ & $\mathrm{HCM}$ & None & - & + & - & - & 15 & 0.0 \\
\hline F-19 & 57 & M & GAS & OHT & - & - & - & + & 25 & 1.8 \\
\hline Mean $\pm S D$ & $50 \pm 15$ & - & - & - & & & & & $18 \pm 6$ & $2.2 \pm 3.5$ \\
\hline
\end{tabular}

Dxn, Digoxin. ACEI, Angiotensin-converting enzyme inhibitor. Dutx, Diuretics. Ca-blkr, Ca antagonists. HCM, Hypertrophic cardiomyopathy. GAS, Graft atherosclerosis. $C A B G$, Coronary artery bypass graft. $P T C A$, Percutaneous transluminal coronary angioplasty. AICD, Automatic implantable cardiac defibrillator. $M V R$, Mitral valve replacement. $A V R$, Aortic valve replacement. $O H T$, Orthotopic heart transplant. +, Administrated. - , Not administrated. $N A$, Not available.

of the subjects $\left(r^{2}=0.09\right)$. Although the EFs were significantly lower in DHD- than in NF-LVs $(29.1 \pm 10.8[n=7]$ vs. $62.5 \pm 5.0 \%[n=4], P<0.0001)$, no significant correlation was found between the $\mathrm{EF}$ and the amplified $\alpha-\mathrm{MyHC} \mathrm{cDNA}$ ratio $\left(r^{2}=0.05\right)$ in the control subjects.

In the F-LVs, the EFs were extremely low (18.1 $\pm 5.9 \%$ $[n=17], P<0.00001$ vs. NF-LV, $P<0.01$ vs. DHD-LV), and there was no statistically significant correlation between the $\mathrm{EF}$ and the amplified $\alpha-\mathrm{MyHC}$ cDNA ratios. No detectable $\alpha$-MyHC mRNA was expressed in four of six F-LV with IDC (F-10-15; Table II). However, there was no statistically significant difference in the values between the patients with IDC (F-10-15, 1.1 $2.5 \%$ ) and those with CAD (F-1-9, 3.2 $\pm 4.5 \%$ ). In addition, there was no relationship between the type of treatment and the amplified $\alpha-\mathrm{MyHC}$ cDNA ratios.

Quantification with RPA. Although we felt quite confident that the assay with RT-PCR was accurate in determining the relative expression level of MyHC mRNA in the myocardium, the composition of $\alpha$-MyHC mRNA in the NF- and DHD-LVs obtained in this study was surprisingly high compared with those suggested by previous reports (7-13). Therefore, RPA was also performed on the same LV specimens and on the additional two atrial myocardium samples, where $\alpha$-MyHC has been shown to be prominent $(8,10-13)$. Fig. 6 shows the representative patterns of protected fragments. The $\alpha$-MyHC mRNA ratios obtained by RPA were in good agreement with those by RT-PCR ( $r^{2}=0.93$; Fig. 7$)$.

\section{Discussion}

Recently, gene expression in failing human hearts has been studied intensively to clarify the molecular and cellular mechanisms in the development of heart failure. We and other groups have reported downregulation of $\beta 1$ adrenergic receptors (24), the angiotensin II AT1-receptor subtype (25), sarcoplasmic reticulum proteins such as $\mathrm{Ca}^{2+}$ ATPase $(26,27)$, phospholamban (28) and the ryanodine receptor (29), and upregulation of the $\mathrm{Na}^{+}-\mathrm{Ca}^{2+}$ exchanger (30) and atrial natriuretic peptide (28) in ventricles from patients with end-stage heart failure. In terms of contractile proteins, Boheler et al. failed to find any difference in the composition of two sarcomeric actins, $\alpha$-skeletal and $\alpha$-cardiac actin, between control and failing human hearts (31).

In this study, we have determined the relative expression levels of the two cardiac MyHC genes in human LV and demonstrated that, in contrast to previous reports (7-13), $\alpha$-MyHC mRNA constitutes a significant amount of the total MyHC gene expression in the LVs of organ donors with no cardiac history and no structural cardiovascular abnormalities. Moreover, chronic heart failure was accompanied by a significant decrease in the amount of $\alpha$-MyHC mRNA.

Amplified $\alpha-M y H C$ cDNA ratios in control donor hearts. The relative values of $\alpha-\mathrm{MyHC}$ expression in control donor hearts (NF- and DHD-LVs) were considerably higher than those of previous reports, in which the $\mathrm{MyHC}$ isoform composition 


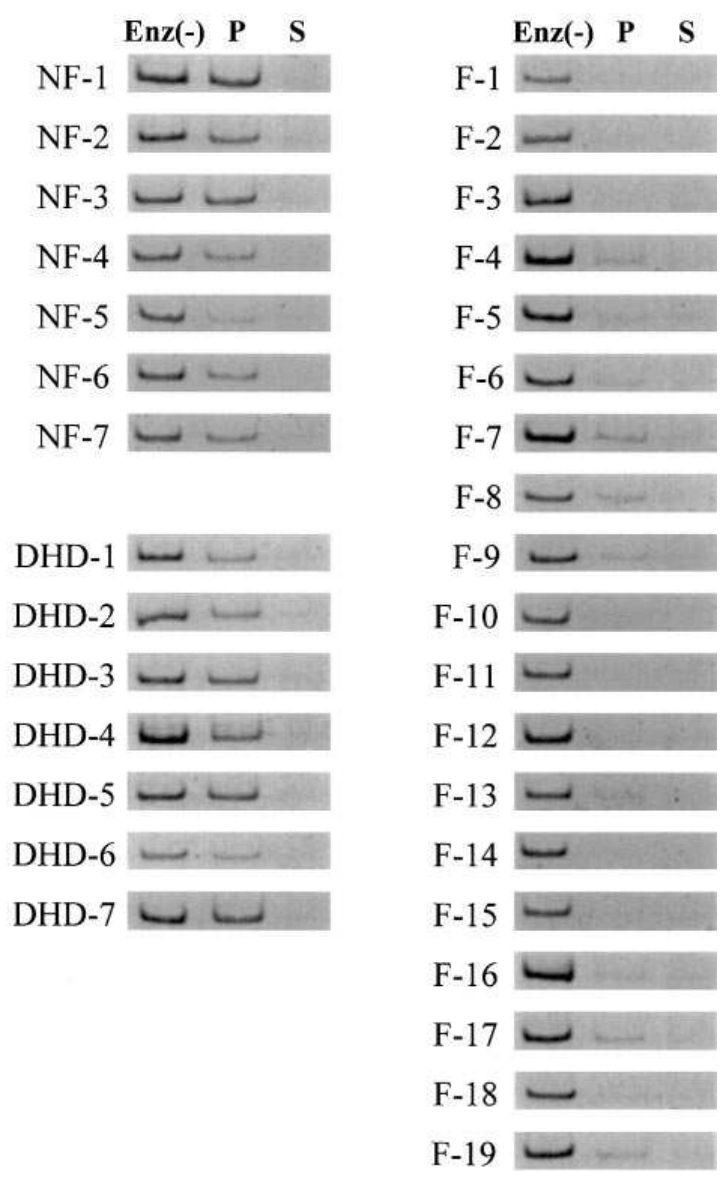

Figure 4. MyHC gene expression in NF, DHD, and F LVs. Enz (-), Incubation without restriction enzyme; thus, the band consists of both $\alpha$ - and $\beta$-MyHC-amplified cDNA. The fragments remaining after digestion with PstI $(P)$ or SacI $(S)$ correspond to the amplified $\alpha$-MyHC cDNA and the background, respectively (see Fig. 1). The calculated amplified $\alpha$-MyHC cDNA ratios are shown in Tables I and II. To control for the presence of genomic DNA, control cDNA reactions in which reverse transcriptase was omitted were prepared in parallel. These were uniformly negative (data not shown).

of the human heart was investigated using several methods (813). Unlike rodent MyHCs, human $\alpha$-and $\beta$-MyHCs are not separated easily by their electrophoretic migration pattern on denaturing or nondenaturing gels (9). In addition, peptide mapping of human ventricular myosin has failed to detect any developmental or pathological differences $(7,10)$. Immunohistochemical analysis was applied to investigate the MyHC isoform composition in the human heart. However, the percentage of anti- $\alpha-\mathrm{MyHC}$ antibody-positive cardiocytes in normal ventricles varied considerably among the reports. Schiaffino, Gorza, and colleagues reported that $<5 \%$ of total cardiac cells were immunoreactive with an anti- $\alpha$-MyHC antibody $(8,11)$, while Bouvagnet et al. reported that $20-88 \%$ of cardiocytes were positive for another anti- $\alpha-\mathrm{MyHC}$ antibody in normal ventricles (12). Tsuchimochi et al. reported with a different $\mathrm{mAb}$ that cardiac muscle fibers were composed almost exclusively of $\beta-\mathrm{MyHC}$ in ventricular myocardium (13). These differences may be caused by differences in the affinity of the antibodies to their epitopes, the conditions for using them (15,
16), or the patient population. In addition, this methodology provides no quantitative information about the amount of $\alpha$-MyHC, merely the proportion of cells expressing the gene. Therefore, it is difficult to quantify the relative expression of $\mathrm{MyHC}$ isoforms in humans by these methods.

There is only one previous report of MyHC mRNA expression in the human heart. Kurabayashi et al. (21) reported that a single normal human ventricle expressed no detectable $\alpha$-MyHC mRNA by Northern blot analysis. In contrast, we observed previously easily detectable $\alpha$-MyHC mRNA in a nonfailing ventricle from a single organ donor by Northern blot analysis (our unpublished observations). However, in that case, the quantification of relative mRNA expression of $\alpha$ - and $\beta$-MyHCs with Northern blotting was not possible because the affinity of the probes specific for $\alpha$ - and $\beta$-MyHC mRNA was different since they derive from the highly diverse $3^{\prime}$ untranslated regions, and standards of pure $\alpha$ - and $\beta-\mathrm{MyHC}$ synthetic transcripts were not included.

Given the discrepancy between our findings and those of previous reports in which antibodies were used to evaluate the expression ratio of $\alpha$ - and $\beta$-MyHC protein, it is important to determine whether the mRNA levels are represented by corresponding amounts of protein. To date, the only posttranscriptional events in MyHC gene expression have been alternative polyadenylation and an alternate single codon splice in $\alpha$-MyHC, neither of which appears to be regulated (32). In vivo studies in rats and rabbits have demonstrated that the synthesis of $\beta$-MyHC and its mRNA levels changed in parallel after pressure overload $(6,33)$. In contrast, a recent study (34) demonstrated a dissociation $\beta$-MyHC mRNA and protein expression after ascending aortic banding in rats. However, in humans, the relationship between MyHC mRNA and protein in the heart has not yet been investigated.

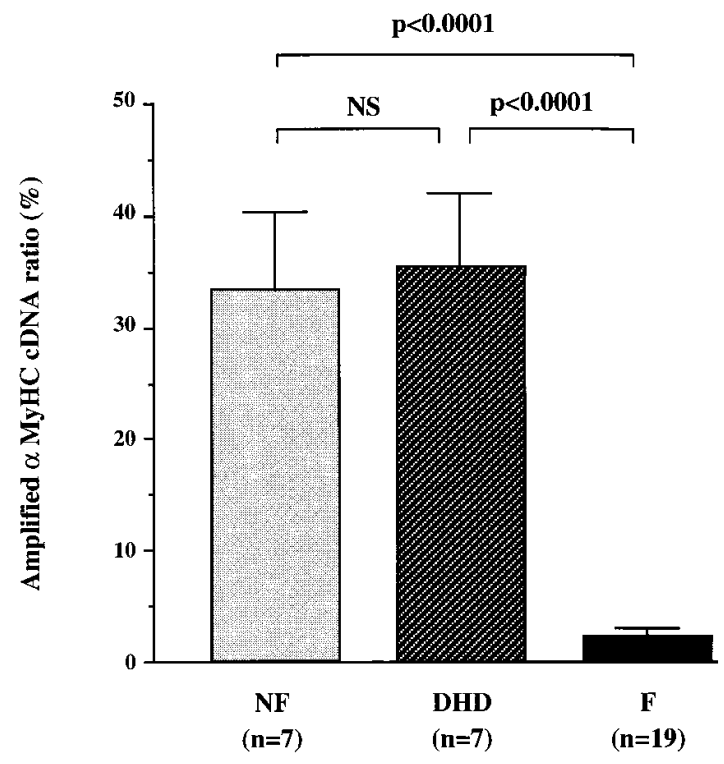

Figure 5. Histograms of amplified $\alpha-\mathrm{MyHC} \mathrm{cDNA}$ ratios of $\mathrm{NF}$, DHD, and F human LVs. Data from each group are presented as mean \pm SEM. One-way ANOVA and Scheffe's multiple comparison tests were applied to assess significance. 


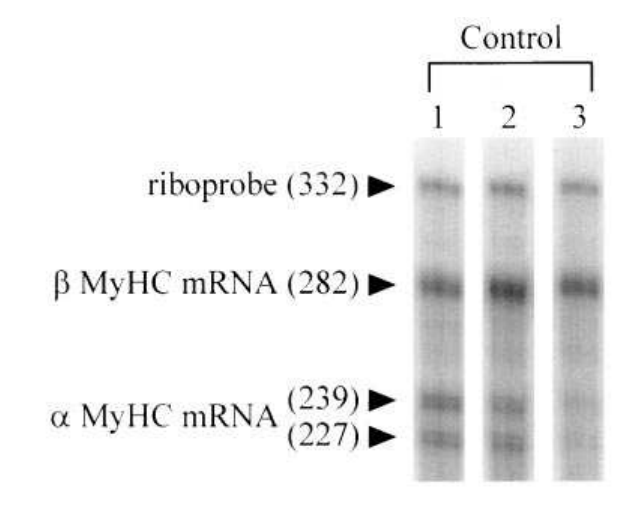

$\alpha$ MyHC mRNA ratio (\%) $\quad \begin{array}{llll}58.4 & 24.0 & 7.1\end{array}$

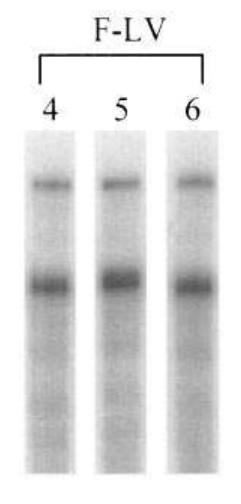

$\begin{array}{lll}4.3 & 1.7 \quad 0\end{array}$
RA

7

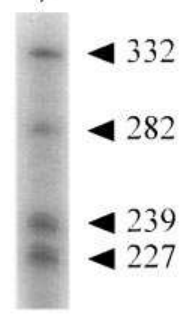

94.1
Figure 6. RPA of $\alpha$ - and $\beta$-MyHC gene expression. Lanes 1-6, Patients DHD-7, NF-6, NF-5, F-1, F-6, and F-11, respectively. Lane 7, MyHC gene expression in an atrial specimen (donor heart, 59-yr-old male). Values under lanes represent the calculated $\alpha$-MyHC mRNA expression ratios (see Methods). Fragment sizes are indicated in nt on the left for lanes $1-6$ and on the right for lane 7 .
It is noteworthy that there was no significant difference in the relative $\alpha$-MyHC mRNA between the NF- and DHD-LVs despite their marked difference in LV EF just before organ harvest. DHD is a type of acute heart failure related to severe brain injury (22). We reported previously that, compared with $\mathrm{NF}$ hearts, right ventricular trabeculae removed from DHD hearts exhibited a profound decrease in contractile response to isoproterenol as well as reduced calcium response (22). Given the lack of difference in the relative $\alpha$-MyHC mRNA expression between NF- and DHD-LVs in this study, it seems likely that decreased intrinsic systolic function per se is not responsible for the alterations of $\mathrm{MyHC}$ isoform composition in heart failure.

The amplified $\alpha-\mathrm{MyHC}$ ratios varied considerably among the patients both in the NF- (7.5-61.9\%) and the DHD-LV groups (15.1-55.0\%). A similar variation was reported previ-

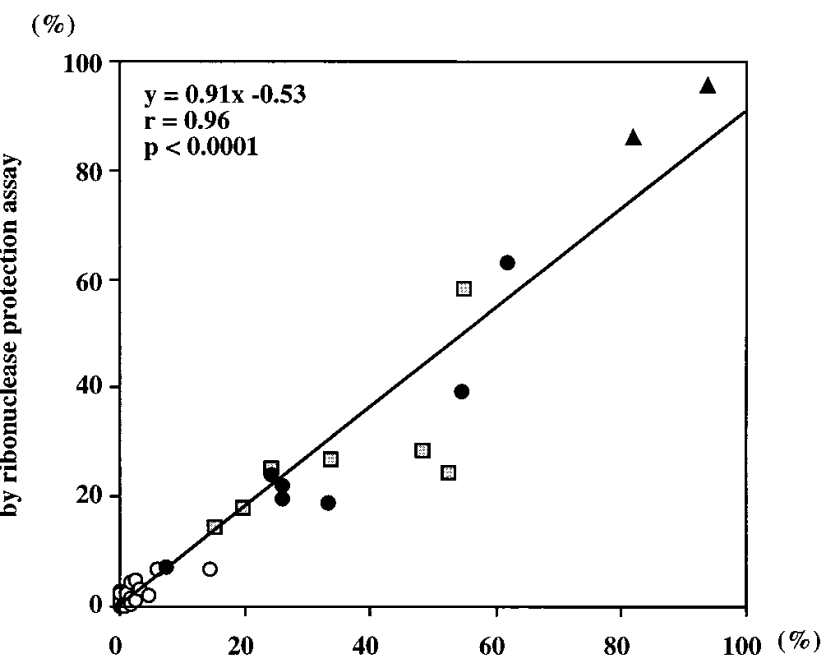

by quantitative RT-PCR

Figure 7. The relationship between the $\alpha$-MyHC mRNA expression ratios determined by quantitative RT-PCR and by RPA. Open and filled circles, F- and NF-LV groups, respectively. Squares, DHD-LVs. Triangles, Values of atrial specimens from two donor hearts. $r=$ correlation coefficient. ously with immunohistochemistry $(11,12)$. These investigators reported that the percentage of myofibers immunoreactive to $\alpha$-MyHC-specific antibody was highly varied among normal individuals and less in the subendocardium than in the subepicardium. In this study, because all transmural specimens were taken from the same region of the LV free wall, the variation in amplified $\alpha$-MyHC ratios is not likely to be due to regional differences in the sample origin but to individual difference.

Differences in amplified $\alpha-M y H C$ cDNA ratios between $N F$ - and $F-L V s$. The amount of $\alpha-\mathrm{MyHC}$ in chronic failing hearts was $<5 \%$ in all but 2 ventricles $(\mathrm{F}-8, \mathrm{~F}-13)$, and in 7 of 19 was undetectable. Assuming that human $\alpha$-MyHC has threefold higher ATPase activity than $\beta$-MyHC $(2,3)$, and that the contractile velocity of muscle expressing a significant amount of $\alpha-\mathrm{MyHC}$ is much higher, it may be that the contractility of failing heart could be improved by increasing the expression of $\alpha$-MyHC (35). However, a determination of MyHC isoform protein and its relation to mRNA abundance in the human heart will need to be made before this conclusion can be proposed.

In interpreting the profile of $\mathrm{MyHC}$ gene expression, it is important to examine the patients' pharmacological status before cardiac explantation. It is well known that the expression of cardiac myosin isoforms is regulated by circulating factors such as thyroid hormone (14). Thyroid status (determined by T4 levels) was available for only three control patients (NF-4, DHD-2 and -5) and was within normal range. All end-stage failing hearts were from subjects who were chemically euthyroid by routine clinical testing. All of the control donor patients in this study were given various doses of dopamine, and three of them were also treated with dobutamine for maintenance of peripheral vascular tone and renal blood flow. They also had been subjected to large amounts of sympathetic stimulation associated with brain injury (22). Thus, the effect of adrenergic stimulation on MyHC isoform shift needs to be considered. However, in this study, the $\alpha$-MyHC mRNA ratio showed no relation to the duration of life support, the dose of dopamine at organ harvest, or their double products. Moreover, the heart failure subjects had also been exposed to increased levels of adrenergic stimulation (36). In previous studies, efforts to demonstrate a role for catecholamines in the regulation of $\mathrm{MyHC}$ expression in cultured cells have produced conflicting results $(37,38)$. In addition, in vivo, because of the phenomenon of receptor desensitization (36), it is diffi- 
cult to equate the effects of brief treatment with adrenergic agonists in cultured cardiac myocytes to in vivo administration. Injecting hypothyroid rats with doses of isoproterenol sufficient to increase intracellular cAMP did not induce $\alpha$-MyHC (39). Likewise, continuous infusion of norepinephrine in euthyroid rats failed to change $\mathrm{MyHC}$ isoform prevalence (40). Recently, we evaluated MyHC expression in right ventricular biopsy specimens from nonfailing and failing (IDC) human hearts, which revealed that the percentage of $\alpha$-MyHC mRNA expression to total MyHC mRNA was threefold less in IDC ventricle than in nonfailing ventricle (41). Moreover, in this study, there was no significant difference in the relative $\alpha$-MyHC mRNA expression between NF- and DHD-LVs despite the fact that DHD hearts exhibit marked uncoupling of $\beta 1$ and $\beta 2$ adrenergic receptors from adenylyl cyclase (22). Thus, it seems unlikely that the administration of adrenergic agonists or acute elevation of endogenous catecholamines played a role in increasing $\alpha$-MyHC mRNA levels in donor hearts.

We were interested in determining whether there was a correlation between $\mathrm{EF}$ and the relative amount of $\alpha$-MyHC mRNA in the F group. However, because of the low levels of both $\mathrm{EF}$ and amplified $\alpha-\mathrm{MyHC}$ cDNA ratio, there was no statistically significant correlation. Although there was no significant difference in the amplified $\alpha-\mathrm{MyHC}$ cDNA ratio between F-LVs with CAD and those with IDC, the values tended to be higher and more varied in the F-LVs with CAD. If one can assume that hemodynamic overload is responsible for the reduction of $\alpha$-MyHC mRNA, the variability may be reasonable, because topographic alterations of myocardial architecture after myocardial infarction (i.e., ventricular remodeling [42]) may induce heterogeneous patterns of increased wall stress in the viable myocardium.

Clinical application of quantitative RT-PCR followed by restriction digestion. Recently, quantitative PCR methods have been used widely for the estimation of mRNA expression in many tissues under physiological and pathophysiological conditions (43). We reported previously using quantitative RTPCR and cardiac biopsy samples that a selective gene expression occurred in the failing human ventricle (28). Because of the tube-to-tube variability in amplification efficiency, an internal control template DNA has to be prepared for each reaction. The template must have primer annealing sites identical to those of its competitor gene and must be a different size than the PCR product to be quantified.

Instead of using a synthetic template, we amplified a 217-bp cDNA fragment with primers identical in sequence in $\alpha$ - and $\beta$-MyHC in this study. This approach is possible because the amplified fragments' sizes are the same, the lengths are short, the sequences of the fragments are $96 \%$ identical, and the two cDNAs were amplified with equal efficiency. The bands were quantified with a fluorescence detection system that was more sensitive than conventional methods, and it allowed us to evaluate a small amount of cDNA produced by PCR from a low number of amplification cycles without radioisotopes. This makes it easier to perform quantification during the exponential amplification phase of PCR. The accuracy of this method was confirmed by RPA performed independently.

The procedure we used can be applied easily to the examination of biopsy samples. Although this method cannot determine the absolute amount of each MyHC mRNA expressed in LVs, it is useful for knowing relative isoform composition, which may be affected by the milieu surrounding cardiocytes, specifically by mechanical overload. Future studies will include the evaluation of biopsies from patients with class II and III heart failure in order to determine the time course of the decrease in $\alpha$-MyHC gene expression. Ladenson et al. reported that, in a single hypothyroid patient with IDC, thyroid hormone replacement increased $\alpha$-MyHC mRNA expression in the right ventricle up to 11-fold, and was accompanied by an improvement in the LV EF from 16 to $37 \%$ (35). Because MyHCs may play a major role(s) in cardiac contraction, potential therapeutics for heart failure might include agents that induce $\alpha$-MyHC gene expression. However, it is obviously important to determine the amount of $\alpha$ - and $\beta$-MyHC protein expression. Such studies are ongoing.

\section{Acknowledgments}

We would like to thank Dr. Doug Robertson for statistical consultation. This work was supported by National Institutes of Health grants 5 R37 HL-50530-04 to Leslie A. Leinwand, and HL-48013 to Michael R. Bristow. Some of the data in this report constitute intellectual prospects licensed to Myogen, Inc., in which Drs. Bristow and Leinwand have an equity interest.

\section{References}

1. Nadal-Ginard, B., and V. Mahdavi. 1989. Molecular basis of cardiac performance. Plasticity of the myocardium generated through protein isoform switches. J. Clin. Invest. 84:1693-1700.

2. Alpert, N.R., and L.A. Mulieri. 1982. Increased myothermal economy of isometric force generation in compensated cardiac hypertrophy induced by pulmonary artery constriction in the rabbit. Circ. Res. 50:491-500.

3. Holubarsch, C.H., R.P. Goulette, R.Z. Litten, B.J. Martin, L.A. Mulieri, and N.R. Alpert. 1985. The economy of force development, myosin isoenzyme pattern and myofibrillar ATPase activity in normal and hyperthyroid rat myocardium. Circ. Res. 56:78-86.

4. Lompre, A.M., K. Schwartz, A. d'Albis, G. Lacombe, N.V. Thiem, and B. Swynghedauw. 1979. Myosin isoenzyme redistribution in chronic heart overload. Nature (Lond.). 282:105-107.

5. Mercadier, J.J., A.M. Lompre, C. Wisnewsky, J.L. Samuel, J. Bercovici, B. Swynghedauw, and K. Schwartz. 1981. Myosin isoenzymic changes in several models of rat cardiac hypertrophy. Circ. Res. 49:525-532.

6. Izumo, S., A.M. Lompre, R. Matsuoka, G. Koren, K. Schwartz, B. NadalGinard, and V. Mahdavi. 1987. Myosin heavy chain messenger RNA and protein isoform transitions during cardiac hypertrophy. J. Clin. Invest. 79:970-977.

7. Schier, J.J., and R.S. Adelstein. 1982. Structural and enzymatic comparison of human cardiac muscle myosins isolated from infants, adult, and patients with hypertrophic cardiomyopathy. J. Clin. Invest. 69:816-825.

8. Gorza, L., J.J. Mercadier, K. Schwartz, L.E. Thornell, S. Sartore, and S. Schiaffino. 1984. Myosin types in the human heart. An immunofluorescence study of normal and hypertrophied atrial and ventricular myocardium. Circ. Res. 54:694-702.

9. Mercadier, J.J., P. Bouveret, L. Gorza, S. Schiaffino, W.A. Clark, R. Zak, B. Swynghedauw, and K. Schwartz. 1983. Myosin isoenzymes in normal and hypertrophied human ventricle myocardium. Circ. Res. 53:52-62.

10. Hirtel, H.O., C.R. Tuchschmid, J. Schneider, H.P. Krayenbuehl, and M.C. Schaub. 1985. Relationship between myosin isoenzyme composition, hemodynamics, and myocardial structure in various forms of human cardiac hypertrophy. Circ. Res. 57:729-740.

11. Schiaffino, S., L. Gorza, L. Saggin, C. Valfre, and S. Sartore. 1984. Myosin changes in hypertrophied human atrial and ventricular myocardium. A correlated immunofluorescence and quantitative immunochemical study on serial cryosections. Eur. Heart. J. 5:95-102.

12. Bouvagnet, P., H. Mairhofer, J.O. Leger, P. Puech, and J.J. Leger. 1989. Distribution pattern of $\alpha$ and $\beta$ myosin in normal and diseased human ventricular myocardium. Basic Res. Cardiol. 84:91-102.

13. Tsuchimochi, H., M. Sugi, M. Kuro-o, S. Ueda, F. Takaku, S. Furuta, T. Shirai, and Y. Yazaki. 1984. Isozymic change in myosin of human atrial myocardium induced by overload. Immunohistochemical study using monoclonal antibodies. J. Clin. Invest. 74:662-665.

14. Swynghedauw, B. 1986. Developmental and functional adaptation of contractile proteins in cardiac and skeletal muscles. Physiol. Rev. 66:710-730.

15. Dechesne, C., J. Leger, P. Bouvagnet, M. Claviez, and J.J. Leger. 1985. Fractionation and characterization of two molecular variants of myosin from adult human atrium. J. Mol. Cell. Cardiol. 17:753-756. 
16. Legar, J., P. Bouvagnet, B. Pau, R. Roncucci, and J.J. Leger. 1985. Levels of ventricular myosin fragments in human sera after myocardial infarction, determined with monoclonal antibodies to myosin heavy chain. Eur. J. Clin. Invest. 15:422-429.

17. Matsuoka, R., K.W. Beisel, M. Furutani, S. Arai, and A. Takano. 1991. Complete sequence of human cardiac alpha-myosin heavy chain gene and amino acid comparison to other myosins based on structural and functional differences. Am. J. Med. Genet. 41:537-547.

18. Epp, T.A., I.M. Dixon, H.Y. Wang, M.J. Sole, and C.C. Liew. 1993. Structural organization of the human cardiac $\alpha$-myosin heavy chain gene (MYH6). Genomics. 18:505-509.

19. Jaenicke, T., K.W. Diederich, W. Haas, J. Schleich, P. Lichter, M. Pfordt, A. Bach, and H.-P. Vosberg. 1990. The complete sequence of the human $\beta$ myosin heavy chain gene and a comparative analysis of its product. $G e$ nomics. 8:194-206.

20. Liew, C.-C., M.J. Sole, K. Yamauchi-Takihara, B. Kellam, D.H. Anderson, L. Lin, and J.C. Liew. 1990. Complete sequence and organization of the human cardiac $\beta$-myosin heavy chain gene. Nucleic Acids Res. 18:3647-3651.

21. Kurabayashi, M., H. Tsuchimochi, I. Komuro, F. Takaku, and Y. Yazaki. 1988. Molecular cloning and characterization of human cardiac alphaand beta-form myosin heavy chain complementary DNA clones. Regulation of expression during development and pressure overload in human atrium. J. Clin. Invest. 82:524-531

22. White, M., R.J. Wiechmann, R.L. Roden, M.B. Hagan, M.M. Wollmering, J.D. Port, E. Hammond, W.T. Abraham, E.E. Wolfel, J. Lindenfeld, et al. 1995. Cardiac $\beta$-adrenergic neuroeffector systems in acute myocardial dysfunction related to brain injury. Evidence for catecholamine-mediated myocardial damage. Circulation. 92:2183-2189.

23. Chomczynski, P., and N. Sacchi. 1987. Single-step method of RNA isolation by acid guanidinium-thiocyanate-phenol-chloroform extraction. Anal. Biochem. 162:156-159.

24. Bristow, M.R., W. Minobe, M.V. Raynolds, J.D. Port, R. Rasmussen, P.E. Ray, and A.M. Feldman. 1993. Reduced $\beta 1$ receptor mRNA abundance in the failing human heart. J. Clin. Invest. 92:2737-2745.

25. Asano, K., D.L. Dutcher, J.D. Port, W.A. Minobe, K.D. Tremmel, R.L. Roden, T.J. Bohlmeyer, E.W. Bush, M.J. Jenkin, W.T. Abraham, et al. 1997. Selective downregulation of the angiotensin II AT1-receptor subtype in failing human ventricular myocardium. Circulation. 95:1193-1200.

26. Mercadier, J.J., A.M. Lompre, P. Duc, K.R. Boheler, J.B. Fraysse, C. Wisnewsky, P.D. Allen, M. Komajda, and K. Schwartz. 1990. Altered sarcoplasmic reticulum Ca-ATPase gene expression in the human ventricle during endstage heart failure. J. Clin. Invest. 85:305-309.

27. Hasenfuss, G., H. Reinecke, R. Studer, M. Meyer, B. Pieske, J. Holtz, C. Holubarsch, H. Posival, H. Just, and H. Drexler. 1994. Relation between myocardial infarction and expression of sarcoplasmic reticulum $\mathrm{Ca}^{2+}$ ATPase in failing and nonfailing human myocardium. Circ. Res. 75:434-442.

28. Feldman, A.M., P.R. Ray, C.M. Silan, J.A. Mercer, W. Minobe, and M.R. Bristow. 1991. Selective gene expression in failing human heart. Quantification of steady-state levels of messenger RNA in endomyocardial biopsies using the polymerase chain reaction. Circulation. 83:1866-1872.

29. Brillantes, A.-M., P. Allen, T. Takahashi, S. Izumo, and A.R. Marks.
1992. Differences in cardiac calcium release channel (ryanodine receptor) expression in myocardium from patients with end-stage heart failure caused by ischemic versus dilated cardiomyopathy. Circ. Res. 71:18-26.

30. Studer, R., H. Reinecke, J. Bilger, T. Eschenhagen, M. Bohm, G. Hasenfuss, H. Just, J. Holtz, and H. Drexler. 1994. Gene expression of the cardiac $\mathrm{Na}^{+}-\mathrm{Ca}^{2+}$ exchanger in end-stage human heart failure. Circ. Res. 75:443-453.

31. Boheler, K.R., L. Carrier, D. de la Bastie, P.D. Allen, M. Komajda, J.J. Mercadier, and K. Schwartz. 1991. Skeletal actin mRNA increases in the human heart during ontogenic development and is the major isoform of control and failing adult heart. J. Clin. Invest. 88:323-330.

32. Sindhwani, R., F. Ismail-Beigi, and L.A. Leinwand. 1994. Post-transcriptional regulation of $\alpha$-cardiac myosin heavy chain gene expression. J. Biol. Chem. 269:3272-3276.

33. Nagai, R., N. Pritzl, R.B. Low, W.S. Stirewalt, R. Zak, N.R. Alpert, and R.Z. Litten. 1987. Myosin isoenzyme synthesis and mRNA levels in pressureoverloaded rabbit hearts. Circ. Res. 60:692-699.

34. Wiesner, R.J., H. Ehmke, J. Faulhaber, R. Zak, and J.C. Ruegg. 1997. Dissociation on left ventricular hypertrophy, $\beta$-myosin heavy chain gene expression, and myosin isoform switch in rats after ascending aortic stenosis. Cir culation. 95:1253-1259.

35. Ladenson, P.W., S.I. Sherman, K.L. Baugman, P.E. Ray, and A.M. Feldman. 1992. Reversible alterations in myocardial gene expression in a young man with dilated cardiomyopathy and hypothyroidism. Proc. Natl. Acad. Sci. USA. 89:5251-5255.

36. Bristow, M.R., R. Ginsberg, W. Minobe, R.S. Cubicciotti, W.S. Sageman, K. Lurie, M.E. Billingham, and D.C. Harrison. 1982. Decreased catecholamine sensitivity and $\beta$-adrenergic receptor density in failing human hearts. N. Engl. J. Med. 307:205-211.

37. Waspe, L.E., C.P. Ordahl, and P.C. Simpson. 1990. The cardiac $\beta$-myosin heavy chain gene is selectively induced in $\alpha 1$-adrenergic receptor-stimulated hypertrophy of cultured rat heart myocyte. J. Clin. Invest. 85:1206-1214.

38. Gupta, M.P., M. Gupta, A. Stewart, and R. Zak. 1991. Activation of alpha-myosin heavy chain gene expression by cAMP in cultured fetal rat heart myocytes. Biochem. Biophys. Res. Commun. 174:1196-1203.

39. Sheer, D., and E. Morkin. 1984. Myosin isoenzyme expression in rat ventricle: effects of thyroid hormone analogs, catecholamines, glucocorticoids and high carbohydrate diet. J. Pharmacol. Exp. Ther. 229:872-879.

40. Bhambi, B., E. Morkin, S. Shroff, R. Tomek, and R. Eghbali. 1990. Regulation and induction of early growth response gene in rat myocardium following norepinephrine treatment. Circulation. 82(Suppl III):231. (Abstr.)

41. Lowes, B.D., W.A. Minobe, W.T. Abraham, R.L. Roden, J.D. Port, E.M. Gilbert, P. Larrabee, and M.R. Bristow. 1997. Down regulation of $\alpha$ - and upregulation of $\beta$-myosin heavy chain in intact, failing human ventricles. J. Am. Coll. Cardiol. 29:422A-423A. (Abstr.)

42. McKey, R.G., M.A. Pfeffer, P.C. Pasternak, J.E. Markis, P.C. Come, S. Nakao, J.D. Alderman, J.J. Ferguson, R.D. Safian, and W. Grossman. 1986. Left ventricular remodeling after myocardial infarction: a corollary to infarct expansion. Circulation. 74:693-702.

43. Wang, A.M., M.V. Doyle, and D.F. Mark. 1989. Quantification of mRNA by the polymerase chain reaction. Proc. Natl. Acad. Sci. USA. 86:97179721. 